\title{
Natação como metáfora da leitura
}

\section{Swimming as a metaphor of reading}

https://doi.org/10.34112/2317-0972a2018v36n72p29-42

\section{Olga Donata Guerizoli Kempinska ${ }^{1}$}

RESUMO: O artigo debruça-se sobre a imagem da natação enquanto uma metáfora da leitura. Partindo das representações da navegação marítima caras à hermenêutica, tais como, por exemplo, o naufrágio com espectador, e nas quais a distância estética se vê afirmada, o texto propõe contemplar alguns dos efeitos emocionais da fruição, tais como o humor, em meios aos quais a distância não mais pode ser mantida.

PALAVRAS-CHAVE: Estética da recepção; distância estética; leitura; metáfora; corpo.

ABSTRACT: The paper analyses the image of swimming as a metaphor of reading. Taking as its starting point the representations of maritime navigation valorized by the hermeneutics, such as for instance the shipwreck with spectator, and by which the esthetic distance is affirmed, the text aims to contemplate some of emotional effects, for example humor, in which the distance can no more be sustained.

KEYWORDS: Reader-response theory; esthetic distance; reading; metaphor; body.

1. Universidade Federal Fluminense, Niterói, RJ, Brasil. 
Natação como metáfora da leitura

Ninguém a bordo sabia nadar, nem mesmo os marinheiros; uma ignorância, aliás, comum

entre os homens do mar.

Victor Hugo

Uma coisa pelo menos é certa: a água e a loucura estarão ligadas por muito tempo nos sonhos do homem europeu.

Michel Foucault

Suave mari magno, sobretudo no desembarque.

Samuel Beckett

Com a emergência das vanguardas no início do século XX mudam as relações estéticas e, por exemplo, o ano de 1912 pode ser pensado como um dos momentos decisivos na história da subversão da distância presente na fruição de um texto literário. Trata-se, de fato, da data da escrita e primeira recepção da Metamorfose de Kafka e da data do afundamento do Titanic. Na mesma época em que os amigos de Kafka soltavam "uma sonora gargalhada” (BROD, 200o, p. 154) ao ouvir a passagem na qual Gregor Samsa acordou metamorfoseado em um inseto monstruoso, o orgulhoso e luxuoso navio avançava a toda velocidade ao encontro do iceberg e desaparecia sob as ondas do Atlântico. Assim, a primeira recepção - dramática, pois Kafka leu sua narrativa em voz alta a um grupo de amigos - do texto que, ao misturar o automatismo do discurso burocrático com a lógica do pesadelo, estimulava o desequilíbrio extremo da relação entre a proximidade e a distância, ao mesmo tempo forçando e proibindo o riso dos fruidores, coincidiu temporalmente com o primeiro naufrágio permeado pelo humor ambivalente:

Cômico que se manifesta em vários níveis. No nível das responsabilidades humanas, não negligenciáveis, parece, mas pensemos na estranha ordem dada às máquinas de seguir à velocidade máxima ao encontro dos icebergs (...). Ficaremos finalmente espantados com a tentativa do último minuto de ficar à altura dramática das circunstâncias, dando à catástrofe, pela substituição por hinos religiosos da música de dança, um acompanhamento musical apropriado (ROSSET, 2009, p. 172-173).

Em 1927 a poeta polonesa Maria Pawlikowska-Jasnorzewska enfatizou esse elemento sinistramente humorístico presente no afundamento do Titanic em um 
breve poema, em que a encenação visual da brusca descida do discurso coincide com a inesperada irrupção da alteridade linguística:

dançavam sonhos leques arco-íris alumiados

alguém sussurrava para alguém: sim - para sempre -

entrou o steward disse e todos ficaram parados

ladies and gentlemen

danger
(PAWLIKOWSKA-JASNORZEWSKA, 2013, p. 118).

Com esse naufrágio desprovido de pureza da tonalidade e com essa recepção perversa do texto kafkiano esgota-se também algo da eficácia daquela metáfora da navegação, que desde a Antiguidade era amplamente utilizada como a imagem das aspirações expansivas do homem ocidental, expressando o ímpeto de seu glorioso percurso pelo mundo. Hans Blumenberg, em seu estudo Naufrágio com espectador. Paradigma de uma metáfora de existência, de 1979, ressaltou a abrangência das metáforas da navegação nos mais diversos domínios da existência humana:

Os seres humanos passam sua vida e fundam suas instituições na terra firme. No entanto, tentam captar o movimento de sua existência sobretudo através de metáforas de uma perigosa viagem marinha. $O$ repertório dessas metáforas náuticas da existência é bastante rico. Inclui costas e ilhas, portos e mares abertos, recifes e tempestades, enseadas e calmarias, velas e lemes, timoneiros e âncoras, bússolas e navegação astronômica, faróis e pilotos (BLUMENBERG, 1997, p. 7).

A metáfora de uma jornada marinha tem a capacidade de abranger diversos aspectos da vida humana, tanto existenciais, quanto econômicos e políticos. O nascimento do homem é, assim, expressado na imagem da embarcação e do naufrágio; o comércio e o dinheiro veem-se traduzidos através do elemento "líquido"; o edifício do estado é comparado a um navio; surge também a analogia entre a situação do observador de um naufrágio e o filósofo. Ao lado dessas aproximações entre a navegação e os domínios da filosofia, da economia e da política, as metáforas náuticas permeiam também o repertório imaginário encenado nas obras literárias do Ocidente, desde Homero, Defoe, Baudelaire, Rimbaud, Melville, Mallarmé e Conrad, até Hemingway, em todas suas odisseias, robinsonadas, pescarias e naufrágios poéticos. 
E como o desmascaram alguns verbetes do malicioso Dicionário das ideias feitas de Bouvard e Pécuchet, o mar é um elemento que "propicia grandes pensamentos", o navegador é "sempre ousado" e o viajante, "sempre intrépido" (FLAUBERT, 1979, p. 540-555). Pois a imagem da navegação enquanto metáfora do movimento do ser humano pelo mundo sempre esteve profundamente relacionada ao perigo inerente à travessia de fronteiras:

Dois pressupostos principais determinam o teor de sentido carregado pelo universo metafórico da viagem marinha e do naufrágio: em primeiro lugar, o mar enquanto uma fronteira naturalmente dada do domínio das atividades humanas e, em segundo lugar, sua demonização enquanto a esfera daquilo que escapa ao conhecimento e à lei, na qual a orientação resulta difícil (BLUMENBERG, 1997, p. 8).

Vale a pena ressaltar que nas imagens náuticas a natureza e a cultura são colocadas em situação de um mútuo desafio. Observemos que essa tensão está presente já nos componentes do repertório náutico descrito por Blumenberg, que podem ser divididos em dois grupos: por um lado, elementos naturais e fenômenos meteorológicos (costas, ilhas, recifes, enseadas, estrelas, tempestades, calmarias), e, por outro, instrumentos, construções e profissões (velas, lemes, âncoras, bússolas, portos, faróis, timoneiros, pilotos). E se a imagem da natação não faz parte do repertório náutico da aventura existencial, que consiste na travessia das fronteiras "naturalmente dadas", é porque esse repertório é configurado enquanto um campo de batalha entre a natureza e a cultura, no qual os dois domínios evitam as relações de continuidade ou complementaridade para, antes, afirmar as de oposição.

Também na literatura a imagem da natação surge inicialmente em oposição à da navegação. A queda na água do bordo de um navio inaugura, em 1933, uma das primeiras narrativas de Gombrowicz, que há de encenar não uma história de conquistas de terras longínquas, nem o declínio do heroísmo dos capitães conradianos nos confins da civilização ocidental, mas, antes, uma grotesca e fantástica perseguição homoerótica pelos mares. Os marinheiros perdem cada vez mais irrevogavelmente as graças do mar. Seria essa uma nova modalidade de "fronteiras naturalmente dadas", inerentes ao imaginário da navegação? Confrontado com o corpo na água, o navio gombrowicziano é profundamente cômico em sua falta de agilidade e de precisão: 
Em 1930, em setembro, navegando para Cairo, caí no Mediterrâneo; caí com um grande barulho, pois o mar estava naquela hora liso, não perturbado com menor onda. No entanto, perceberam a minha queda só no minuto seguinte, quando o navio já tinha se afastado um quilômetro e meio, e quando finalmente o viraram e voltaram em minha direção, o fervoroso capitão colocou uma velocidade excessiva e o colosso errou o lugar em que eu sufocava na água salgada. Mais uma vez viraram e miraram, mas também daquela vez, o navio passou ao lado com a velocidade de um trem e parou longe demais. Essa manobra foi repetida umas dez vezes (GOMBROWICZ, 1982, p. 29).

Na mesma época, uma encenação das fronteiras "naturalmente dadas" - genéricas, profissionais e geracionais - está presente no livro Duas luas de Maria Kuncewiczowa, na cena na qual uma moça vai nadar no rio. É o barco, dirigido por um policial, que claramente figura aqui as convenções sociais. A jovem e rebelde nadadora Mena, que faz parte de um grupo de artistas a perturbar com seus livres costumes a vida da pequena e pitoresca cidade de Kazimierz, experimenta a natação como uma experiência erótica e como um exercício da liberdade:

Desceu para o rio como para a cama. Ficou toda envolta em flocos frios e murmurantes, deixou-se levar pelas ondas ou pelos sonhos. Sabia nadar muito bem: as pernas e os braços inconscientemente efetuavam os movimentos certos, a cabeça podia livremente entregar-se ao fogo do sol. (...)

De repente, um casco preto surgiu em seu caminho; Mena dirigiu-se à esquerda para contorná-lo - o casco também seguiu para esquerda. Antes que tivesse tempo para pensar em algo, fortes garras a prenderam e puxaram para cima. Gritou e remexeu-se... As garras não soltaram, mas a água terminou e os joelhos bateram contra as pranchas (KUNCEWICZOWA, 1989, p. 81-82).

Como na cena da moça pescada pelo policial que tenta "salvá-la”, nas primeiras imagens da natação, que irrompem na representação literária nas primeiras décadas do século $\mathrm{XX}^{2}$, o corpo do nadador se opõe ao barco. Mas, com tempo, essa oposição há de se transformar em uma substituição e a imagem da natação passa a remeter não apenas à transgressão, mas também à conquista. No entanto, à dife-

2. Um dos precursores da tematização da natação foi Walt Whitman: "Onde a água espirrada por nadadores e mergulhadores refresca o calor do meio dia” (2014, p. 93); "Agora quero você nadando com coragem” (2014, p. 123); "O nadador pelado na piscina. . visto enquanto nada pelo sal translúcido" (2014, p. 175). 
rença das façanhas obtidas por meio da navegação, a conquista representada pela natação nunca começa com uma construção exterior e tecnológica, a de um navio, mas, antes, com a posse do próprio corpo. Paul Valéry, o discípulo insubmisso do mestre do naufrágio poético, Mallarmé, é um dos primeiros a relatar, em 1943, a relação íntima e prazerosa entre a atividade do corpo e a água, exaltando-a como um amoroso excesso do real. E trata-se aqui do corpo desde a nuca até os dedos dos pés, sem a cabeça, acima da qual o punho do Mestre mallarméano, na iminência de afundar - o suicídio e o apocalipse são, de fato, componentes prediletas de todo naufrágio -, desesperadamente apertava os dados:

Mas lançar-se na massa e no movimento, agir até os extremos, e da nuca até os dedos dos pés; virar-se nessa pura e profunda substância; beber e soprar a amargura divina, é para mim um jogo comparável ao amor, a ação na qual meu corpo inteiro se faz todo signos e todo forças, como uma mão se abre e se fecha, fala e age. Aqui o corpo todo se dá, se retoma, se concebe, se gasta e quer esgotar suas possibilidades (VALÉRY, 2008, p. 317).

O movimento do corpo relaciona-se nas imagens da natação sobretudo à imagem da respiração. A experiência de aprender a nadar enquanto um exercício da respiração é, por exemplo, narrada por Randall, uma das crianças que no livro Lignes de faille, de 2006, de Nancy Huston, relatam seu mal de origem. O menino que se empenha em desenhar reiteradamente corpos sem tronco, é obcecado pela imagem do corpo fragmentado, despedaçado. A experiência da natação na piscina revela-se para esse menino de origem judia uma forma benéfica de alienação iniciática e prazerosa:

Ainda não sei nadar mas inventei um jogo no qual fico de cócoras embaixo d'água expirando o ar pelo nariz e pela boca depois salto no ar inspirando, depois submerjo expirando e assim vai - alto baixo alto baixo - entro em um segundo estado com o peso e o barulho da água e o ritmo do movimento, poderia fazer isso durante horas, mas depois de um tempo meu papai me pega e diz que tem que voltar a trabalhar (HUSTON, 2006, p. 156).

Submergir-expirar e, em seguida, emergir-inspirar, trazer o ar dentro de si para expirá-lo dentro d'água e capturar o ar para dentro de si ao emergir fora d'água: 0 exercício iniciático de Randall, descrito por Huston em uma língua não materna, que se constrói aqui como uma linguagem infantil dominada pela justaposição e mal articulada em termos lógicos, foi interrompido. E seu inacabamento parece 
remeter a um fracasso da busca por um ritmo que tornasse possível a vivência harmoniosa da relação conflituosa entre o dentro e o fora. Essa busca, que é encenada pelo exercício de respiração, consiste, afinal, em um aprendizado da articulação vital dos desdobramentos corpo/mundo, ar/água, dentro/fora. A importância do ritmo envolvido na respiração e no movimento do corpo, que permite permanecer no espaço "não natural" da água, também é tematizada pela imagem da natação. Associando a experiência da natação com o espaço pré-natal, Siri Hustvedt havia, por sua vez, tematizado justamente a presença da vivência que é bruta e indistinta pelo fato de ser alheia à linguagem. É esse espaço alinguístico que é parcialmente reencontrado "quando nos encolhemos para dormir, quando comemos, quando alguns de nós tomam banho ou nadam” (HUSTVEDT, 2006, p. 9).

Como ainda veremos, a própria experiência da natação na piscina anula a validade da oposição entre a natureza, por um lado, e a cultura, por outro, tornando-se, dessa forma, análoga à representação do corpo desterritorializado, do corpo-ciborgue (Cf. HARAWAY, 2009). Com efeito, aprender a respirar para nadar é uma tarefa paradoxal na qual se desaprende e reaprende aquilo que é considerado como mais natural. Nadar é praticar uma forma de "respiração estrangeira", tal como se pratica uma língua estrangeira. Respirar e falar são, por sua vez, questões de vida ou morte. E é justamente dessa forma, enquanto a conquista do corpo ameaçado pela doença, morte ou assimbolia, que a imagem da natação surge no texto poético Angst de Hélène Cixous: "Quando se aprendeu a nascer, é como com a natação, o nascimento fica para sempre em seu corpo, como um traço de uma potência sempre prestes a se fazer sentir. Você se levanta, avança, separa as águas com os braços" (CIXOUS, 1977, p. 25). E é também nesse sentido, como uma conquista do próprio corpo, que a história da nadadora brasileira Maria Lenk é citada na recente narrativa de Maria Cecília Gomes dos Reis A vida obscena de Anton Blau:

E reconhece o mesmo na nadadora Maria Lenk. Filha de imigrantes, depois do susto de uma dupla pneumonia, Lenk começa a praticar natação nas águas do rio Tietê, onde são realizadas as provas de nado da cidade, e inicia assim uma carreira de sucessos, com o marco de ser a primeira atleta sul-americana a disputar em 1932 os Jogos Olímpicos de Los Angeles - junto a outros 68 atletas brasileiros, a nadadora custeia a própria viagem vendendo o café que levam no porão do navio (GOMES DOS REIS, 2011, p. 49). 
Em uma continuação da imagem da navegação enquanto uma travessia de fronteiras, chama a atenção nas narrativas de Gombrowicz, de Huston e de Gomes dos Reis a associação da natação com a ideia do movimento, com a imigração, mas também com a desterritorialização. Notemos de passagem que o "Grande nadador" kafkiano, o vencedor das Olimpíadas, que confessava publicamente não saber nadar, também era estrangeiro na própria cidade natal:

Vim da Olimpíada em Antwérpia, onde bati o recorde mundial de natação. Subi na escada da estação em minha cidade natal - onde estará ela? - e olhei para a multidão indistinta no crepúsculo. Uma moça, cujo rosto acariciei, furtivo, envolveu-me habilmente em uma faixa, na qual estava escrito em uma língua estrangeira: Para o vencedor olímpico (KAFKA, 2004, p. 767).

Se a imagem da natação se torna capaz de articular a experiência da desterritorialização, é porque ela desafia a noção do "natural" enquanto oposta à do "artificial". Prolongando e subvertendo a ideia da passagem de fronteiras presente na metáfora da navegação, é possível observar, de fato, um deslocamento da atividade, que abandona seu meio natural (mar, rio) para ser incorporada pela cidade, tanto por seu espaço (piscina) quanto por suas instituições (Jogos Olímpicos). Todos esses elementos - a piscina, o ritmo, a respiração, o corpo - coincidem com a invenção, na literatura, da experiência da natação na piscina, que envolve uma atividade e um espaço ambíguos e heterogêneos. Pois o repertório imaginário da natação tende sobretudo a confundir aquelas fronteiras "naturalmente dadas" que as imagens da navegação enfatizavam. $O$ corpo na água, a respiração na água, o erotismo, o ritmo do movimento do corpo na água e, como veremos, o próprio espaço da piscina, confundem as oposições entre o natural e o cultural. Ainda em 1834, um artigo de jornal intitulado "Sobre a natação" tropeçava grotescamente naquelas oposições centrais para as imagens da navegação, entre a natureza e a cultura e entre a barbárie e a civilização. $\mathrm{O}$ texto, ao definir a atividade enquanto uma "arte", ou seja, uma técnica, insistia na falta da imagem da natação na narrativa da história da cultura ocidental, e sublinhava sua posição ao lado do bárbaro, do selvagem e da natureza animal:

A natação é a arte de se manter na água e, ao mesmo tempo, de fazer um movimento para frente através desta. 
Como a natação não é natural ao homem, é evidente que em alguma época devia ser desconhecida da raça humana. Ora, não há relatos sobre sua origem na história de nenhuma nação; não que existam nações bárbaras que não possuam a arte da natação e até mesmo mais perfeitamente desenvolvida do que entre os povos civilizados.É, no entanto, provável que essa arte, embora não perfeitamente natural, seja sempre adquirida pelos seres humanos em estado selvagem, a partir da imitação dos animais que, na maioria, nadam naturalmente. De fato, isso parece ser bem o caso, a ponto de os nadadores mais excelentes terem recomendado àqueles que desejam aprender a arte que guardassem sempre consigo alguns sapos em um tubo de água e que imitassem os movimentos através dos quais estes se deslocam nesse elemento (The Dublin Penny Journal, 1834, p. 346-347).

É interessante justapor essa reflexão sobre uma técnica artificial que resulta da imitação do mundo natural (dos sapos!), e até do bárbaro, às reflexões sobre a natação formuladas em 1934 por Marcel Mauss. Em seu estudo "A noção de técnica do corpo", ao sublinhar a dimensão cultural da disposição física do ser humano, Mauss evoca como seu primeiro exemplo justamente as mudanças observadas nas técnicas da natação elaboradas ao longo de algumas décadas. Na passagem citada surpreende, no entanto, sobretudo a comparação entre o barco e o corpo do nadador, que parece suceder à máquina ao imitá-la:

Posteriormente - eu mesmo o percebia -, assisti à mudança das técnicas do nado ainda no período de nossa geração. Um exemplo nos fará compreender isso imediatamente, a nós psicólogos, biólogos, sociólogos. Outrora nos ensinavam a mergulhar depois de ter aprendido a nadar. E, quando nos ensinavam a mergulhar, nos diziam para fechar os olhos e depois abri-los dentro d'água. Hoje a técnica é inversa. Começa-se toda aprendizagem habituando a criança a ficar dentro d'água de olhos abertos. Assim, antes mesmo que nadem, as crianças são treinadas sobretudo a controlar os reflexos perigosos mas instintivos dos olhos, são antes de tudo familiarizadas com água, para inibir seus medos, criar uma certa segurança, selecionar paradas e movimentos. Há, portanto, uma técnica do mergulho e uma técnica da educação do mergulho que foram descobertas em meu tempo. E vejam que se trata claramente de um ensino técnico, e que há, como para toda técnica, uma aprendizagem do nado. Por outro lado, nossa geração, aqui, assistiu a uma mudança completa de técnica: vimos o nado a braçadas e com a cabeça fora d'água ser substituído pelas diferentes espécies de crawl. Além disso, 
perdeu-se o costume de engolir água e de cuspi-la. Pois os nadadores se consideravam, em meu tempo, como espécies de barcos a vapor (MAUSS, 2003, p. 402).

Sendo uma arte que "não é natural ao homem", mas que, enquanto uma "técnica do corpo" pode ser adquirida pela imitação dos animais, mas também dos barcos, a atividade da natação desafia a oposição entre natureza e cultura. E é justamente essa impossibilidade de se manter separadas as duas dimensões, a natural e a cultural, que é melhor encenada nas representações de espaço e da experiência da piscina³. Dentre muitas, aquela que me pareceu a mais evocativa foi construída pela escritora japonesa Yoko Ogawa. Na narrativa Piscina, de 1990, que tem como cenário o espaço da piscina, o mergulho na água é observado e interiorizado pela adolescente Aya, que narra em primeira pessoa seu amor por Jun. Estar dentro do corpo de um animal, ficar escondida em um lugar invisível em condições normais, flutuar dentro da barriga da mãe e, finalmente, estar dentro do outro: as imagens da intimidade suscitadas pela experiência da piscina ganham em intensidade na narrativa de Aya:

Aqui sempre faz calor: é como se eu tivesse sido engolida por um enorme animal. Passados uns minutos, meu cabelo, meus cílios, até a blusa do meu uniforme escolar estão todos impregnados pelo calor e pela umidade e fico coberta por uma película molhada vagamente cheirando a cloro. (...)

Vi algumas imagens de câmaras subaquáticas. O quadro é completamente preenchido pela água azul e profunda e o saltador cai dentro apenas para girar e dar um impulso na direção da superfície. Esse giro embaixo d'água chega a ser mais bonito do que o próprio salto: os tornozelos e as mãos cortam a água majestosamente e o corpo fica completamente envolto na pureza da piscina. Quando as mulheres saltam, seus cabelos ondulam embaixo d'água como se fossem movimentados por uma brisa, e elas parecem calmas como crianças fazendo exercícios de respiração profunda. (...)

Será que Jun deixa flutuar à vontade seu corpo na piscina, tal como um feto faz na barriga da mãe? Como eu gostaria, para a alegria do meu coração, de vê-lo nadando aí, perfeitamente livre (OGAWA. 2009, p. 17).

3. A representação cinematográfica da natação na piscina mereceria um estudo à parte. Limito-me a citar alguns títulos de filmes que a articulam com os problemas da oposição entre a natureza e a cultura e da desterritorialização: Azul de Krzysztof Kieslowski (1993), Dente canino de Giorgos Lanthimos (2009) e Incêndios de Denis Villeneuve (2011). 
Erotizada, pois inseparável da beleza do corpo de Jun e do desejo, a experiência da piscina revela-se também para Aya a origem de uma sensação de liberdade e de plenitude em meio a uma infância paradoxal e perversa no orfanato dirigido pelos pais da protagonista. De fato, que forma de desterritorialização poderia ser mais culpada? A experiência da piscina enquanto experiência do amor ${ }^{4}$ será irremediavelmente perdida após a revelação da crueldade de Aya, que maltrata as crianças menores: "Nunca mais saltará na piscina dentro de mim, encoberta agora pela névoa das lágrimas da menina. As ondas de arrependimento eram suaves, mas eu sabia que iam se espalhar concentricamente para sempre" (OGAWA, 2009, p. 28). É interessante comparar a sensação sinestésica da narrativa de Ogawa com aquela não menos sinestésica experiência da água relatada em 1942 por Bachelard:

Se eu tivesse que reviver pessoalmente o mito filosófico da estátua de Condillac, que encontra o primeiro universo e a primeira consciência nos cheiros, ao invés de dizer, como ela, "sou um cheiro de rosa", deveria dizer "sou um cheiro de hortelã, cheiro de hortelã aquática”. (...) Ao querer estudar a vida das imagens da água, preciso devolver seu papel dominante ao rio e às fontes do meu país natal.

Nasci em uma região de riachos e rios, em um canto da Champagne ondulada, em Vallage, assim chamada por causa da grande quantidade de seus vales. $\mathrm{O}$ mais belo lar seria para mim no fundo de um vale, na beira de uma água corrente, na sombra curta de salgueiros e vimes. E com a chegada de outubro e de suas brumas acima do rio...

Gosto ainda de acompanhar um riacho, de caminhar ao longo de sua beira, no bom sentido, no sentido da água que corre, da água que leva a vida além, para o vilarejo vizinho (BACHELARD, 1942, p. 11).

Vários elementos aproximam as duas experiências da água, a relatada na narrativa de Ogawa e a descrita por Bachelard: o cheiro refrescante, a presença e a importância da água, sua relação com o lar e com a infância. No entanto, todos esses componentes podem ser distribuídos de uma forma contrastante: cheiro de cloro - cheiro de hortelã; água da piscina artificial - água da corrente natural; saltar

4. A representação da piscina torna-se mais ambivalente, mas não menos intensa, nas narrativas "Plagiat" e "Backstroke" de Ogawa, nas quais se relaciona não apenas com o amor, mas também com a opressão emocional e política. Cf. OGAWA, Yoko. La Bénédiction inattendue. Paris: Actes Sud, 200o, p. 37-68; Les Paupières. Paris: Actes Sud, 2007, p. 117-141. 
e mergulhar - caminhar ao longo e contemplar; nascer em um orfanato na cidade - nascer em uma casa entre vales e rios; sair do lar - voltar ao lar.

Ainda assim, observemos que essa distribuição contrastante, na verdade, dificilmente corresponde à oposição fácil entre a natureza (o rio) e a cultura (a piscina). Em primeiro lugar por causa da relação ambígua que o corpo do nadador mantém com a água. De fato, se na Piscina de Ogawa a poética da água claramente remete ao elemento em seu estado artificial, ela envolve também a atividade que engaja diretamente o corpo do nadador, mobilizando o ritmo de sua respiração e de seu movimento. Além disso, em Ogawa, a falta de um lar territorializado é acompanhada pela escolha e pela interiorização de um espaço artificial, o da piscina, enquanto, em Bachelard, a "mesma" poética exige a presença da natureza, da territorialidade e da distância contemplativa do corpo do espectador, que passeia ao longo do rio. Assim, a oposição entre o artificial e o natural revela-se falaciosa na comparação das duas poéticas, pois a atividade de mergulhar e de nadar, que envolve e impregna diretamente o corpo inteiro, desde a pele, passando pelos músculos, e até a respiração, remete a uma experiência bem mais "natural" e também muito mais intima do que as caminhadas ao longo de um rio que engajam apenas a visão, o olfato - cujo envolvimento na experiência estética é sem dúvida um dos aspectos mais ousados da poética bachelardiana - e a imaginação.

Na teoria da literatura, a metáfora da natação já foi utilizada, mas não no âmbito da reflexão sobre a estética e a teoria da recepção: ela se tornou uma das imagens importantes na descrição da escrita feminina, da poética feminina da criação. Assim, ao narrar poeticamente a dinâmica da "chegada à escrita", Hélène Cixous introduz a equivalência entre o movimento do parto, o da natação e o da escrita através da imagem do "trabalho do sopro", no qual se dá uma coincidência amorosa da passividade e da atividade: "Sua bela potência então! Dar à luz como se nada, brincando com a resistência da carne, do mar, trabalho do sopro no qual se anula a noção de 'domínio' (maîtrise), um corpo do seu próprio corpo, a mulher se segue, se junta, se esposa" (CIXOUS, 1986, p. 37). Essa coincidência do ativo e do passivo, indispensável na poética da criação cixousiana para a relação plural entre o texto e o desejo, pode ser também fecunda para a consideração do alcance estético do efeito humorístico. Soltar uma risada durante a leitura não é deixar-se levar pelo texto, que envolve a abdicação do controle ativo da distância? $\mathrm{O}$ riso do leitor parece apontar, nesse sentido, para uma "leitura feminina". Pois a risada, ao engajar o corpo do leitor, irrompe na atividade fruidora e provoca justamente uma anulação 
do controle da distância estética. O leitor ridente, tal um nadador ou uma mulher no trabalho do parto, passa, de fato a encarnar o movimento da leitura, "um corpo do seu próprio corpo".

Ao expor a abrangência da imagem da navegação enquanto a metáfora da existência humana, Blumenberg ressaltou também a existência na cultura ocidental de um paralelo entre a distância do espectador do naufrágio e a distância estética do fruidor de uma obra de arte. De fato, a posição do espectador, que efetua uma viagem imaginária para o contexto representado, mas que permanece a salvo do perigo representado em uma obra, perfeitamente corresponde à posição de um fruidor clássico. Mas observemos que a distância que resulta dessa segurança foi, na verdade, há séculos desafiada pelas obras cômicas, que, ao acompanhar como uma sombra os grandes gêneros trágicos, recusavam a idealização inerente à distanciação clássica e tematizavam a presença bruta e imediata do corpo. Através dessa tematização, as obras cômicas propunham ao fruidor uma experiência do "aqui e agora", tão diferente da "arte do afastamento" (PAVEL, 1996), tanto temporal e espacial, quanto emocional.

A natação como uma metáfora da leitura corresponde a essa veia subterrânea do cômico. Ela começa pelo corpo e, ao contrário da navegação, engaja-o direta e inteiramente, eliminando, dessa forma, a validade da distância, a possibilidade de ocupar um lugar no navio ou a posição de um espectador do naufrágio a salvo do perigo. A situação do nadador remete, antes, à atividade performática do fruidor que se engaja diretamente - corpo e alma - na produção da representação. Assim, ao confundir o dentro e o fora, o natural e o artificial, o humano e o animal, o dado e o construído, e ao transformar o corpo em um primeiro objeto de conquista existencial, a imagem da natação pode substituir a da navegação também na compreensão do alcance da experiência estética, contribuindo dessa maneira para as tentativas atuais de sua reformulação. Um leitor ridente, que mobiliza seu corpo no ato da recepção é um leitor-nadador. Uma risada - tal como o choro e tal como a excitação sexual -, que irrompe no ato da leitura, transforma a leitura em um mergulho que subverte a distância estética.

\section{REFERENCIAS:}

BACHELARD, G. L'eau et les rêves. Essai surl'imagination de la matière. Paris: Librairie José Corti, 1942. BECKETT, S. Malone morre. Trad. A. H. Souza. São Paulo: Globo, 2014. BLUMENBERG, H. Shipwreck with Spectator. Paradigm of a Metaphor for Existence. Cambridge: The MIT Press, 1997. 
BROD, M. Kafka. Buenos Aires: Emecé, 2000.

CIXOUS, H. Angst. Paris: des femmes, 1977.

CIXOUS, H. La venue à l'écriture. Paris: des femmes, 1986.

FLAUBERT, G. Bouvard et Pécuchet. Paris: Gallimard, 1979.

FOUCAULT, M. História da loucura. Trad. J. T. Coelho Neto. São Paulo: Martins Fontes, 2010.

GOMBROWICZ, W. Zdarzenia na brygu Banbury. Gdańsk: Wydawnictwo Morskie, 1982.

GOMES DOS REIS, M. C. A vida obscena de Anton Blau. São Paulo: Editora 34, 2011.

HARAWAY, D.; KUNZRU, H.; TADEU, T. (Org. e Trad.). Antropologia do ciborgue. As vertigens do pós-humano. Belo Horizonte: Editora Autêntica, 2009.

HUGO, V. L'homme qui rit. In: HUSTON, N. Lignes de faille. Actes Sud, 2006.

. Euvres complètes XII. Paris: J. Hetzel \& A. Quantin, 1883.

HUSTVEDT, S. A Plea for Eros. London: Sceptre, 2006.

KAFKA, F. Das Werk. Sämtliche Werke. Frankfurt am Main: Zweitausendeins, 2004.

KUNCEWICZOWA, M. Dwa księżyce. Lublin: Wydawnictwo Lubelskie, 1989.

MAUSS, M. Sociologia e antropologia. Trad. P. Neves. São Paulo: Cosac \& Naify, 2003.

OGAWA, Y. The Diving Pool. London: Random House e-books, 2009.

PAWLIKOWSKA-JASNORZEWSKA, M. A Amante do piloto. Revista Literária em Tradução (n.t.), n. 7, 2013.

PAVEL, T. L'art de l'éloignement. Essai sur l'imagination classique. Paris: Gallimard, 1996.

ROSSET, C. Logique du pire. Paris: PUF, 2009.

The Dublin Penny Journal. v. 2, n. 96, 1834, p. 346-347.

VALÉRY, P. Tel Quel. Paris: Gallimard, 2008.

WHITMAN, W. Folhas de relva. Trad. R. Garcia Lopes. São Paulo: Iluminuras, 2014.

\section{SOBRE A AUTORA}

Olga Kempinska possui graduação e mestrado em Filologia Românica (Uniwersytet Jagiellonski de Cracóvia, Polônia) e doutorado em História Social da Cultura (Pontifícia Universidade Católica do Rio de Janeiro). Atualmente é professora de Teoria da Literatura no Departamento de Ciências da Linguagem da Universidade Federal Fluminense. Além de vários artigos e traduções, publicou, em 2011, o livro Mallarmé e Cézanne: obras em crise (NAU) e, em 2017, Klov (7Letras). Tem experiência nas áreas de Teoria da Literatura, Teoria da Arte e Teoria da Tradução, com ênfase na relação entre mímesis e emoções. Dirige o grupo de pesquisa CNPq Estéticas do deslocamento.

E-mail: olgagkem@gmail.com.

Recebido em 22 de fevereiro de 2017 e aprovado em o2 de setembro de 2017. 